\title{
Biopsy-based optimization and calibration \\ of a signal-intensity-ratio-based MRI method (1.5 Tesla) in a dextran-iron loaded mini-pig model, enabling estimation of very high liver iron concentrations
}

\author{
Peter D. Jensen ${ }^{1}(\mathbb{D}) \cdot$ Asbjørn H. Nielsen $^{2}$ (D) $\cdot$ Carsten W. Simonsen $^{3} \cdot$ Kenneth K. Jensen $^{3} \cdot$ Martin Bøgsted $^{1,4}$. \\ Anne B. H. Jensen ${ }^{5}$. Benedict Kjaergaard ${ }^{6,7}$
}

Received: 11 June 2021 / Revised: 26 December 2021 / Accepted: 28 December 2021 / Published online: 17 January 2022

(c) The Author(s) 2022

\begin{abstract}
Objective Magnetic resonance imaging (MRI)-based techniques for non-invasive assessing liver iron concentration (LIC) in patients with iron overload have a limited upper measuring range around $35 \mathrm{mg} / \mathrm{g}$ dry weight, caused by signal loss from accelerated T1-, T2-, T2* shortening with increasing LIC. Expansion of this range is necessary to allow evaluation of patients with very high LIC.

Aim To assess measuring range of a gradient-echo R2* method and a T1-weighted spin-echo (SE), signal intensity ratio (SIR)-based method ( $\mathrm{TE}=25 \mathrm{~ms}, \mathrm{TR}=560 \mathrm{~ms}$ ), and to extend the upper measuring range of the SIR method by optimizing echo time (TE) and repetition time (TR) in iron-loaded minipigs.

Methods Thirteen mini pigs were followed up during dextran-iron loading with repeated percutaneous liver biopsies for chemical LIC measurement and MRIs for parallel non-invasive estimation of LIC (81 examinations) using different TEs and TRs.

Results SIR and R2* method had similar upper measuring range around $34 \mathrm{mg} / \mathrm{g}$ and similar method agreement. Using $\mathrm{TE}=12 \mathrm{~ms}$ and $\mathrm{TR}=1200 \mathrm{~ms}$ extended the upper measuring range to $115 \mathrm{mg} / \mathrm{g}$ and yielded good method of agreement.

Discussion The wider measuring range is likely caused by lesser sensitivity of the SE sequence to iron, due to shorter TE, leading to later signal loss at high LIC, allowing evaluation of most severe hepatic iron overload. Validation in iron-loaded patients is necessary.
\end{abstract}

Keywords Magnetic resonance imaging · Quantitative imaging · Iron overload $\cdot$ Liver iron concentration · Experimental animal models

\begin{tabular}{llll}
\multicolumn{2}{l}{ Abbreviations } & LME & Linear mixed effect \\
CI & Confidence interval & LoA & Limits of agreement \\
ICP-OES & Inductively coupled plasma-optical emission & MRI & Magnetic resonance imaging \\
& spectroscopy & ROI & Region of interest \\
GRE & Gradient echo & SE & Spin echo \\
LIC & Liver iron concentration & SI & Signal intensity
\end{tabular}

Peter D. Jensen

d222615@dadlnet.dk

1 Department of Hematology, University Hospital, Aalborg, Denmark

2 Department of the Built Environment, Aalborg University, Aalborg, Denmark

3 Department of Radiology, Imaging Research Unit, Aalborg University Hospital, Aalborg, Denmark

4 Department of Clinical Medicine, Aalborg University, Aalborg, Denmark

5 The Faculty of Medicine, Aalborg University, Aalborg, Denmark

6 Biomedical Research Laboratory, Aalborg University Hospital, Aalborg, Denmark

7 Department of Cardiothoracic Surgery, Aalborg University Hospital, Aalborg, Denmark 
SI L Signal intensity of liver tissue

SI M Signal intensity of muscle tissue

SIR Signal intensity ratio

TE Echo time

TR Repetition time

\section{Introduction}

Iron overload may develop in conditions with abnormally increased intestinal iron absorption, as in patients with hereditary hemochromatosis and patients with iron-loading anemias (e.g. B-thalassemia) and can be caused by chronic treatment with blood transfusions or both [1]. In hereditary hemochromatosis, the excess iron is primarily stored within the liver [2], while in patients with transfusional iron overload, the liver accounts for approximately 70 to $80 \%$ of the total body iron stores [3], while the rest is primarily deposited within the spleen [3]. The excess iron is sequestered as ferritin particles and hemosiderin aggregates [4]. During progressive iron accumulation, the body's capacity for safe sequestration of excess iron may be overwhelmed [5], eventually leading to hepatocellular injury [6], liver fibrosis or even cirrhosis [7-9], cardiomyopathy, and heart failure [10-13], endocrinal dysfunction [14], and reduced long-term survival $[10,12]$. In $\beta$-thalassemia and other iron-loading anemias, the risk of these complications is shown to be associated with the liver iron concentration (LIC): LIC exceeding $17 \mathrm{mg} / \mathrm{g}$ dry weight are associated with hepatocellular damage [15] and increased risk for cardiac iron overload [16-19].

The current gold standard to quantify the total body iron burden is by chemical measurement of the LIC in a percutaneous liver biopsy [20,21]. This is a consequence of the fact that the liver represents the dominant iron storage organ in the body [22], and the existing evidence for a close, direct relationship between the total body iron and the LIC [16, 20, 23]. Repeated LIC measurements enable monitoring changes in total body iron burden in patients with transfusional iron overload on iron chelation therapying to evaluate the effectiveness of the therapy $[24,25]$.

Today, non-invasive techniques are widely used for the estimation of LIC instead of the chemical measurement in a percutaneous liver biopsy because of the risk of bleeding complications [26-28]. Recent guidelines advocate estimating LIC noninvasively by magnetic resonance imaging (MRI) to identify patients with iron overload and to guide titration of chelation therapy [29-31].

The basis for using MRI for non-invasive estimation of the LIC is that ferritin and hemosiderin iron accelerate $\mathrm{T} 1$ relaxation, $\mathrm{T} 2$ relaxation, and $\mathrm{T} 2 *$ signal decay, causing signal loss on especially on T2-weighted spin-echo (SE) and $\mathrm{T} 2 *$-weighted gradient echo (GRE) MR images [32].
Close relationships have been demonstrated between these relaxation parameters and LIC [33-42], which likely have promoted the widespread use of MRI for non-invasive estimation of LIC [35-40, 42-52].

Non-invasive estimation of LIC can also be performed by superconducting magnetic susceptometry [53-55]. This method is based on the change in the magnetic susceptibility of the liver in the presence of iron [32]. The measured magnetic field variation is directly related to the amount of tissue iron [56]. This is different in MRI: MRI does not image the iron directly. Instead, it detects the effect of iron on water protons in the investigated liver tissue [32]. Susceptometers are only accessible at a limited number of centers [53, 54, 57], while MRI scanners are widely available today. This may partly explain why MRI is the primary approach today for the non-invasive estimation of LIC [45].

In general, there are two MRI-based strategies for estimation of LIC, by relaxometry, based on measurement of absolute R2 [36, 42], or R2* [35-37, 39, 40, 44, 46] and by methods measuring the signal-intensity ratio (SIR) between liver and skeletal muscle, acting as a reference tissue [43, 47], assessed either from SE [38, 47-52] or GRE sequences $[38,39,43]$.

The methods differ among other things regarding prevalence in use, extent of calibration, and measuring range: The $\mathrm{R} 2 *$ method is in most widespread use in clinical practice, likely because it is a faster and easier method than the R2 method [42].

The most widely used SIR method is that of Gandon et al. [43], which is based on GRE sequences. In earlier studies, SE sequences have been used for the SIR method $[38,47-52]$. We have for many years used a SIR method at our Department of Radiology, based on a T1-weighted SE sequence [47], for non-invasive estimation of the LIC in clinical settings and research in iron overload $[47,48]$. The method uses an echo time (TE) of $25 \mathrm{~ms}$, a consequence of scanner limitations when the method was calibrated. As far as we know, the method is not in clinical use at other centers.

The best-calibrated method in use is an R2 method, known as FerriScan ${ }^{\circledR}$ [42]. The method uses a multi-slice single-spin echo (SE) pulse sequence [25]. Its calibration is based on liver biopsies from 105 patients ( 23 with hereditary hemochromatosis, 50 patients with thalassemia (nine patients had been treated with regular blood transfusion and iron chelation therapy), and 32 patients had hepatitis) [42].

The best-calibrated R2* method is based on a breathhold single GRE pulse sequence [36]. Its calibration was based on biopsies from 22 patients ( 9 patients had thalassemia major and 2 had intermedia, 10 had sickle cell disease and one had Blackfan-Diamond syndrome) [36]. Only the FerriScan ${ }^{\circledR}$ method has been approved as a clinical device for the assessment of liver iron by regulatory authorities in the USA, Canada, Europe, and Australia [58]. 
The method of Gandon et al. [43] uses five breath-hold GRE pulse sequences, obtained by adjusting the flip angle or the echo time (TE) to modulate image weighting, to generate T1-weighted, proton-density-weighted, or mild, moderately, or heavily $\mathrm{T} 2 *$-weighted images. The calibration is based on 139 patients, who were scheduled to undergo liver biopsy for either suspicion of hepatic iron overload or management of chronic hepatitis [43].

The calibration of our method [47] is based on biopsies from eight patients (five patients had hereditary hemochromatosis, two had transfusion-dependent myelodysplastic syndrome, and one had hepatitis) [47].

All methods have a limited upper measuring range. The upper limit of the SIR method is around 30 to $35 \mathrm{mg} / \mathrm{g}$. This is because, in our hands, at these LIC levels, the signal intensity of liver tissue (SI L) approaches background noise. Although the method covers the main part of the patients with iron overload referred to our department for estimation of LIC, we encounter patients with higher LIC levels and cannot evaluate them properly. The upper limit of the measuring range of the SIR method of Gandon et al. [43] is around $20 \mathrm{mg} / \mathrm{g}$ and relaxation measurements of $\mathrm{R} 2 *$ are capable to estimate LIC levels up to $35-40 \mathrm{mg} / \mathrm{g}$, depending on the scanner type [24]. The upper limit of the R2 method is not known, but LIC measurements up to $43 \mathrm{mg} / \mathrm{g}$ have been published [42].

The objective of the present study was as follows:

To compare our SIR method with an R2* method.

To investigate if the upper limit of the measuring range of our SIR method might be extended by an optimization of the underlying SE sequence. The idea was that the SI L will decay later at increasing LIC by reducing TE from 25 to $12 \mathrm{~ms}$.

To investigate the effect of six different repetition times (TR) on the agreement between MRI measures of LIC and biopsy LIC.

To study the usefulness of the skeletal muscle as a tissue reference.

We investigated these issues in a mini-pig model of iron overload, induced by dextran-iron loading, because this model enables estimation of MRI measures of LIC and parallel measurement of biopsy measures of LIC, by providing easy access to repeated percutaneous liver biopsies.

\section{Material and methods}

\section{Animals, animal care, and iron-loading:}

This study includes data from 14 female Göttingen mini pigs, obtained from the barrier unit at Ellegaard Göttingen mini-pigs A/S, Dalmose, Denmark. Animal facilities, principles of laboratory and animal care were as described earlier [59] and conformed to the requirements of the Danish Animal Experiments Inspectorate (Stationsparken 31-33, DK-2600 Glostrup, Denmark). The mini pigs were from 6 to 8 months of age when included in the study. They were followed up with 1- to 3-month intervals for up to 21 months with transcutaneous liver biopsies and parallel MRI for assessment of hepatic $\mathrm{T} 2 *$, hepatic SIR, and myocardial $\mathrm{T} 2 *$. The myocardial $\mathrm{T} 2 *$ data have already been published recently [60]. MRI of the liver was always performed around an hour before the liver biopsy.

Iron loading was performed by weekly, intramuscular injections with dextran iron (Uniferon ${ }^{\circledR}, 200 \mathrm{mg} \mathrm{Fe} / \mathrm{ml}$, Pharmacosmos A/S, Roervangsvej 30, 4300 Holbæk, Denmark, product number 474508), as used earlier in rabbits and rats for induction of iron overload [61]. The dose, recommended by the manufacturer, for 1-3-day-old piglets is one $\mathrm{ml}(200 \mathrm{mg} \mathrm{Fe})$ once (equaling about $139 \mathrm{mg} \mathrm{Fe} / \mathrm{kg}$ body weight). The applied dose in the present study was from 5 to $140 \mathrm{mg} \mathrm{Fe} / \mathrm{kg} /$ week. The dextran-iron injections were admistered into the buttocks. A flow diagram illustrates the principles of iron loading by injections and its timely relation to the examinations of the mini pigs (Fig. 1A). Table 1 gives the dose and the duration of iron loading for each pig.

Pig 4 died during the first MRI/biopsy session due to bleeding complications after the liver biopsy. The data of this pig were excluded from the study, leaving 13 pigs. Dextran-iron injections were always given immediately after the liver biopsy had been taken. At the end of the study, 81 MRI scans with parallel biopsy LIC measurements were available for image analysis. Figure 2 illustrates for each figure, presented in the Results, the number of investigated pigs, and for each pig the dosing of dextran iron (mg Fe/kg/week) and duration of iron loading at each time point of parallel MRI/biopsy investigation during follow-up. Due to limited housing capacity, MRI/biopsy sessions were performed at different time points during the iron loading and follow-up, explaining the individual timelines of the pigs.

\section{Anaesthetization of the animals:}

Before each intramuscular injection of dextran iron, the animals were anesthetized with a single dose of Zoletil ${ }^{\circledR} 50$ Vet $(50 \mathrm{mg} / \mathrm{ml})$, containing $8.3 \mathrm{mg} / \mathrm{ml}$ tiletamine hydrochloride, $8.3 \mathrm{mg} / \mathrm{ml}$ zolazepam hydrochloride, $8.3 \mathrm{mg} / \mathrm{ml}$ xylacin, $8.3 \mathrm{mg} / \mathrm{ml}$ ketaminol, and $1.7 \mathrm{mg}$ butorphanol (Virbac, 1ère avenue $2065 \mathrm{~m}$ LID-06516 Carros, France, product number 568527). The dose was $10 \mathrm{mg} / \mathrm{kg}$ body weight, according to the manufacturers' recommendation for dogs $(7-10 \mathrm{mg} / \mathrm{kg}$ body weight), as described earlier [62]. Before MRI scan, and invasive procedures with biopsies, the pigs were anesthetized with repeated doses of Zoletil ${ }^{\circledR} 50$ Vet. The trachea was intubated with a $6.5 \mathrm{~mm}$ cuffed endotracheal tube. Before breath-hold, during the $\mathrm{T} 2 *$ investigation, general 
Fig. 1 Flow diagram of iron loading and examinations of the mini pigs. A gives a timeline for iron loading by weekly dextran-iron injections (vertical arrows) and repeated biopsy/ MRI sessions. B illustrates the procession of the liver biopsies for the assessment of LIC. BW is the bodyweight of the pig

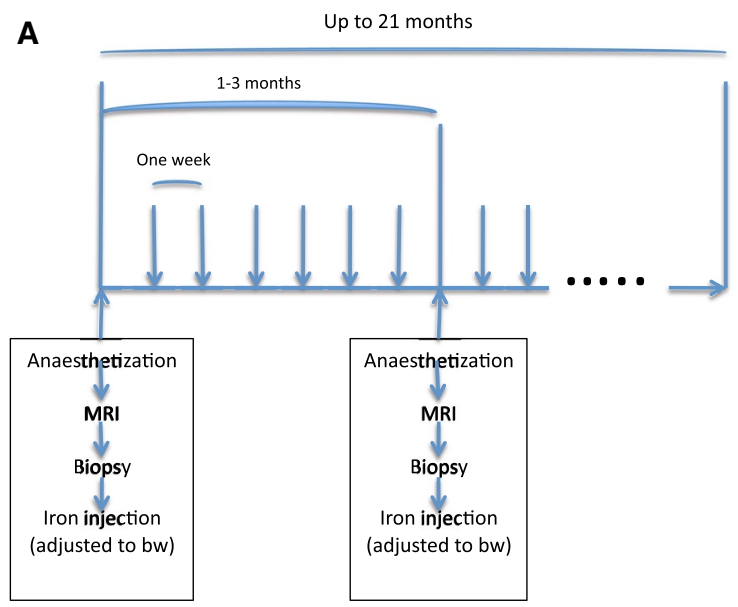

B

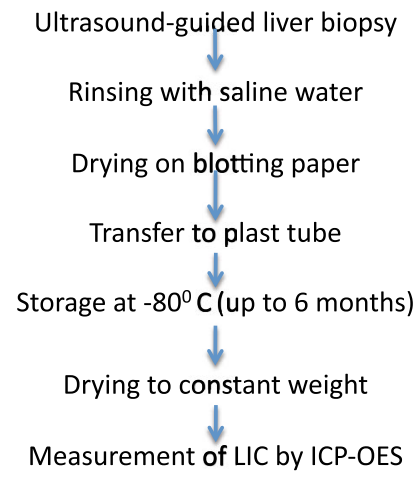

Table 1 Details on iron-loading with dextran iron of 14 mini pigs

\begin{tabular}{lll}
\hline Pig no & Dose (mg Fe/kg/week) & Months \\
\hline 1 & 125 & 15 \\
2 & 5 & 21 \\
3 & 10 & 21 \\
4 & died after 1. biopsy & \\
5 & 20 & 13.5 \\
6 & 30 & 2.5 \\
7 & 35 & 13 \\
8 & 140 & 10.5 \\
9 & 7.5 & 13.5 \\
10 & 10 & 13.5 \\
11 & 50 & 14 \\
12 & 100 & 14 \\
13 control & 0 & 0.5 \\
14 control & 0 & 0.5 \\
\hline
\end{tabular}

In pig 2 and 3 the dose was increased to $35 \mathrm{mg} / \mathrm{kg} /$ week after 12 months of iron loading

anesthesia was achieved by the addition of $1.2 \%$ sevoflurane (Sevoflurane ${ }^{\circledR}, 1 \mathrm{ml} / \mathrm{ml}$, Baxter, Soeborg, DK, product number 023608). A dedicated MRI-compatible respirator (Servo ventilator 900c, Siemens, Germany) maintained artificial ventilation $\left(\mathrm{N}_{2} 0: \mathrm{O}_{2}\right.$ mixture was $\left.2: 1\right)$ between breath holds during MRI [63].

\section{Sampling and procession of liver biopsies:}

A schematic of the procedures is given in Fig. 1B. Ultrasound-guided [64] percutaneous liver biopsies were taken. Biopsies were taken by use of biopsy needle Bard ${ }^{\circledR}$ Biopsy$\mathrm{Cut}^{\circledR}$ (14-gauge $\times 160 \mathrm{~mm}$, Bard, Covington, Georgia, USA, product number 451416). Biopsies were immediately transferred to a 1.5-ml Eppendorf tube ${ }^{\circledR}$ (Eppendorf AG,
Hamburg, Germany, product number 0030 120.086) containing $0.9 \%$ isotonic sodium chloride solution for rinsing for blood. Afterward, the biopsy was placed on blotting paper (Whatman ${ }^{\circledR}$ filter paper, Merck KGaA Darmstadt, Germany, product number WHA10340810) for about a minute and thereafter transferred to another dry $1.5 \mathrm{ml}$ Eppendorf tube ${ }^{\circledR}$ for storage at $-80^{\circ} \mathrm{C}$.

\section{Chemical assessment of hepatic tissue iron concentration}

The LIC is given as $\mathrm{mg} / \mathrm{g}$ dry liver tissue. Before measuring the LIC, the biopsy was dried at $95 \mathrm{C}$ for 3 days to constant weight. Immediately thereafter, the biopsy was weighted. The liver sample weight was between 0.36 and $4.5 \mathrm{mg}$ (mean \pm Std: $2.52 \pm 1.11 \mathrm{mg}$ in 81 samples). A detailed description of the subsequent microwave-assisted acid digestion of the samples, followed by elemental analysis of the digested samples, using inductively coupled plasmaoptical emission spectroscopy (ICP-OES) has been given earlier [59].

\section{MRI for assessment of hepatic SIR and T2*}

All MRI scans were performed on a clinical General Electric (GE) 1.5 T Discovery 450 (GE Healthcare, Chicago, IL, USA) at the Imaging Research Unit, Department of Radiology, Aalborg University Hospital, Denmark. The software package of the scanner was version 24 . For measurement of the SI L/SI M-ratio, a T1-weighted standard respiratorycompensated SE sequence (GE Healthcare, Chicago, IL, USA) was used. The coil configuration was a body coil. Examinations were performed with the pig in a supine position. Four axial slices through the center of the liver and the paraspinal muscles were imaged. Scanning parameters are given in Table 2. 
Fig. 2 Individual pig timelines of dextran-iron loading and time points of investigations. Each panel illustrates for each figure, presented in the Results, the number of investigated pigs, and for each pig (identified by numbers) the dosing of dextran iron in $\mathrm{mg} \mathrm{Fe} / \mathrm{kg} /$ week and the duration of iron loading (months) at each time point of MRI/biopsy during follow-up. In Figs. 7 and 8, not all pigs had a scan at $\mathrm{TR}=300 \mathrm{~ms}$. Pigs that had this scan, are illustrated in E. For further details see Materials and Methods
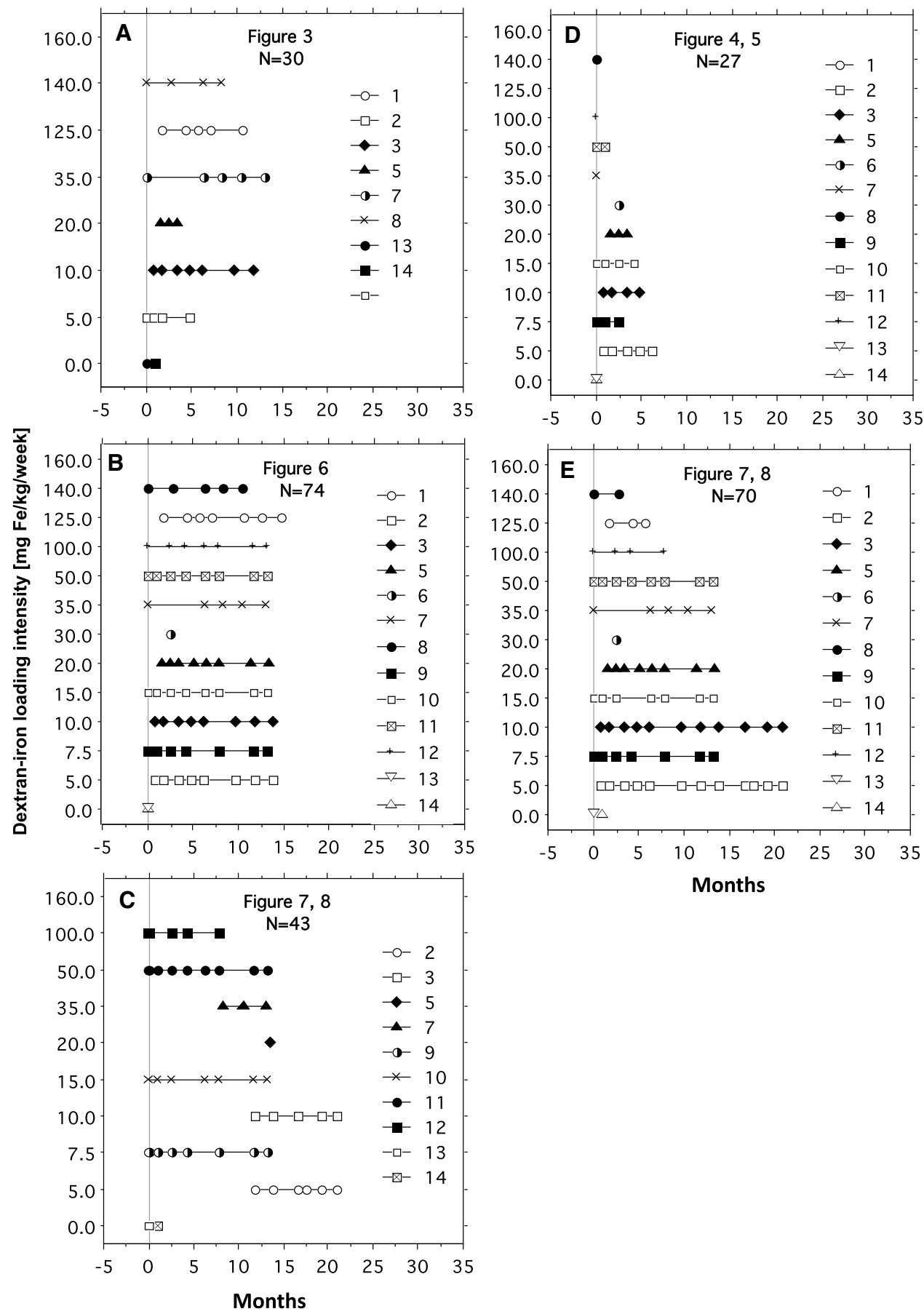

Months
For measurement of $\mathrm{T} 2 *$, a spoiled fast-gradient singleecho sequence (GE Healthcare, Chicago, IL, USA) was used. Coil configuration was GE 8 channel HD cardiac phased array (GE Healthcare, Chicago, IL, USA). The coil was placed straight on the center of the MR table and the center of the coil was at the level of the xiphoid process. The pig was in a supine position. Slice orientation was as used for the assessment of SIR of liver tissue. Scanning parameters are given in Table 2.

\section{Image analysis}

Measurement of the mean SI L and the mean signal intensity of muscle tissue (SI M) for calculation of the SI L/SI M-ratio was performed in a slice that simultaneously visualized the liver and the paraspinal muscle (m. erector spinae). SI measurements were derived from a region of interest (ROI) of $10 \times 10 \mathrm{~mm}$ of size, placed in an area of homogeneous liver tissue, avoiding vessels and other sources of artifacts, as illustrated in Fig. 3A, B. 
Table 2 Magnetic resonance imaging parameters

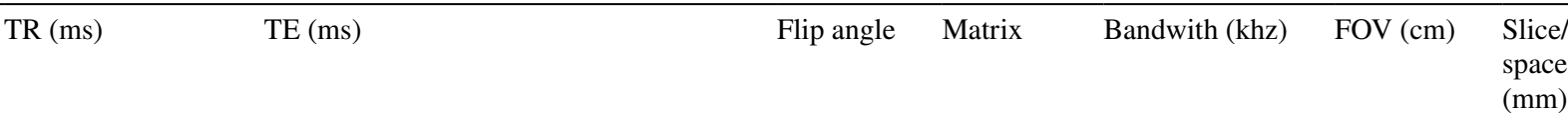

\begin{tabular}{|c|c|c|c|c|c|c|c|}
\hline \multicolumn{8}{|c|}{ Sequence } \\
\hline \multirow[t]{2}{*}{ GRE } & 10 & $\begin{array}{l}1.0,2.2,3.5,4.7,6.0,7.2,8.5,9.7 \\
10.9,12.2,13.4,14.7,15.9,17.2\end{array}$ & 10 & $128 \times 128$ & 83.3 & 38 & $8 / 1.5$ \\
\hline & & $\begin{array}{c}\text { At high LIC } *: 0.9,1.2,1.6,1.9,2.3,2.6 \\
2.9,3.3,3.6,4.0,4.3,4.7,5.0,5.3,5.7\end{array}$ & & & & & \\
\hline SE & $\begin{array}{l}300,400,500,600 \\
800,1000,1200\end{array}$ & 12 and 25 & - & $160 \times 160$ & 20.38 & 40 & $8 / 3$ \\
\hline
\end{tabular}

FOV field of view

*Set of TRs used when the SI L approached background levels when scanning livers with high LIC
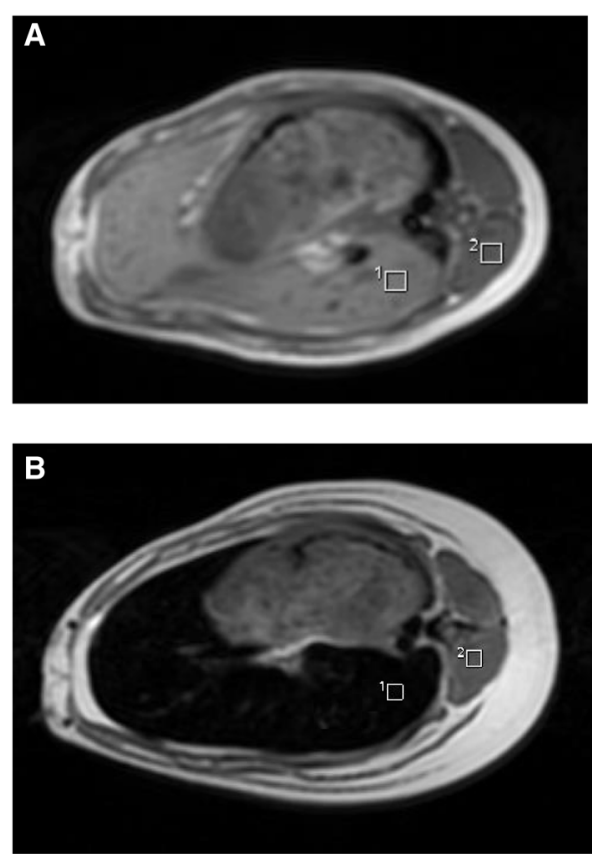

Fig. 3 SIR method for measurement of the SI L/SI M-ratio and its inter-observer reproducibility. A, B show a transverse slice through the center of the liver and the paraspinal muscle of an anesthetized mini pig (no.12) before and after loading with dextran iron (100 mg $\mathrm{Fe} / \mathrm{kg} /$ week for 14 months). Rectangles represent ROIs for the measurement of mean SI L and mean SI M. C The inter-observer repro-

For calculation of hepatic T2*, the StarMap analysis tool (GE Healthcare, Chicago, IL, USA) was used. If the data plot of SI L against TE showed a plateau in the later echo time images, a truncation method was used [65]. Image analysis was performed by an experienced observer, who was blinded to the results of the biopsy LIC measurements.

When investigating the inter-observer reproducibility of SI L/SI M-ratio measurements (Fig. 3C, D), both observers were also blinded to each other. The reproducibility was assessed in 30 scans. They were selected from the 81
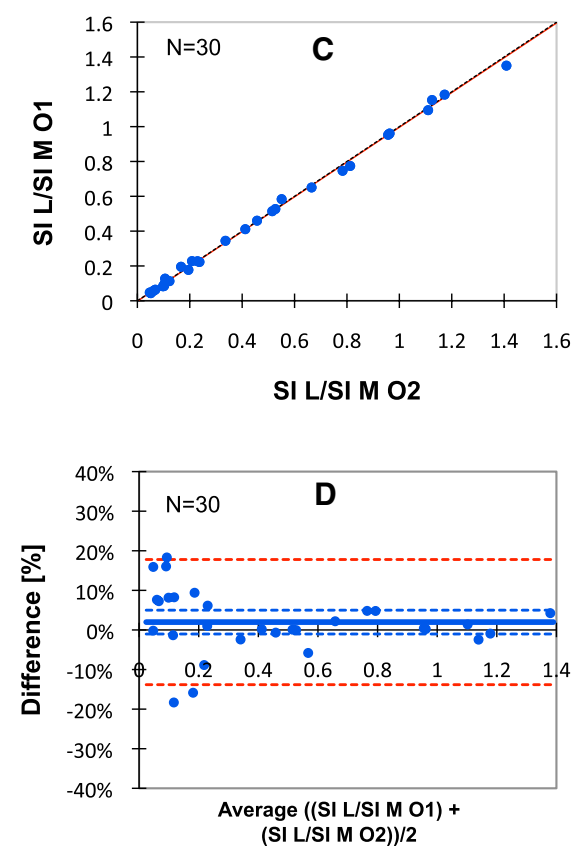

ducibility and agreement between observers 1 and 2, given with the line of identity. D Inter-observer reproducibility investigated by Bland-Altman analysis (same data as C). SI L/SI M-ratio percentage differences are plotted against the mean SI L/SI M-ratios, assessed by the two observers. The full line represents bias with 95\% CI (broken, blue lines). LoAs are indicated by broken, red lines

available MRI examinations, having parallel biopsy LIC measurements available, in a way that ensured coverage of the LIC range of interest ( 1 to $135 \mathrm{mg} / \mathrm{g}$ ).

Figure 3D shows the Bland-Altman analysis of interobserver SI L/SI M-ratio percentage differences plotted against the mean SI L/SI M-ratio for the two observers. The bias was $1.99 \%$ with a $95 \%$ confidence interval (CI) from -1.03 to $8.07 \%$. The limits of agreement (LoAs) were between -13.82 and $17.79 \%$. The disagreement was largest at SI L/SI M $<0.2$, reflecting LIC values of more 
than $115 \mathrm{mg} / \mathrm{g}$. When excluding these LIC values, a bias of $0.24 \%$ was found with a $95 \%$ CI from -1.61 to $2.09 \%$ and with LoAs between -7.04 and $7.52 \%$.

\section{Human calibration curve}

When investigating the transferability of the calibration curve, obtained from the pig model, to patients, we used the human calibration, still in use at our Department of Radiology for our SIR method [47]. The calibration curve is implemented in an in-house software package. The package also enables correction of the SI L/SI M ratio for the use with different TRs during image acquisition, with no correction, if TR $=684 \mathrm{~ms}$. To adjust the SI L/SI M-ratios for the difference in TR, we used the following correction functions, implemented in the package [47]:

$$
(\mathrm{SI} \mathrm{L} / \mathrm{SI} \mathrm{M})_{\text {adjusted }}=\mathrm{SI} \mathrm{L} / \mathrm{SI} \mathrm{M} \times \mathrm{TR}+\alpha\left(\mathrm{T}_{0}-\mathrm{TR}\right)
$$

where $T_{0}$ is $\mathrm{TR}=684 \mathrm{~ms}$. $\alpha$ is approximated by a fourthdegree polynomial, which describes the relation between SI L/SI M (x) and TR [47]as follows:

$$
\begin{aligned}
\alpha= & -1.98 \mathrm{e}-2+3.77 \mathrm{e}-4 x-2.40 \mathrm{e}-6 x^{2} \\
& +4.82 \mathrm{e}-9 x^{3}-2.00 \mathrm{e}-12 x^{4}
\end{aligned}
$$

\section{Statistics}

Upper limits of normal were calculated as mean $+(2 \times \mathrm{SD})$. Inter-observer agreement was assessed by the Bland-Altman method [66]. Bias, upper and lower 95\% LoAs between biopsy LIC values and LIC estimates, predicted from SI L/ SI M-ratio-based calibration curves, were also assessed by the Bland-Altman method.

Exponential model fit of biopsy LIC to SI L or SI L/SI M-ratio was investigated by exponential least-square regression analysis. As data were not normally distributed, when testing the whole data set (Kolmogorov-Smirnov test), linear relationships between SI L/SI M-ratio, SI L, R2*, and log-transformed biopsy LIC values were investigated by Spearman Rank test. Regression lines (calibration curves) were calculated by Passing-Bablok regression analysis. The Cusum test for linearity [67] was used to test the applicability of the Passing-Bablok method [68].

The data were generated by investigating the same pig several times during dextran-iron loading to obtain a wide range of LIC values, while keeping the number of pigs acceptably low, for animal ethical and economic reasons. The drawback of this strategy was the potential generation of nesting effects from each pig. Therefore, when searching for the best calibration curve, with the lowest variance, describing the relationship between SI L/SI M-ratios, SI L values, and biopsy LIC values at different TRs, and when studying the usefulness of the muscle reference, we used linear mixed-effects (LME) models [69]. Two LME models were considered with log-LIC as the dependent variable, pig-id as a random effect, and an interaction term between TR and SI L/SI M-ratio or SI L as independent variables. For each model, a variance function was estimated, where the residual variance is proportional to an exponential function of an interaction between a TR-dependent parameter and the SI L/SI M-ratio and SI L values, respectively. Model control was performed by inspecting the standardized residuals as a function of the predicted values. Pointwise standard deviations, as a function of the SI L/SI M-ratios and SI L values, were plotted for each of the models.

$P$ values $<0.05$ were used to define a significant difference.

The LME models were estimated using R, version 4.03, and the R-package nlme [69]. Bland-Altman analysis, Passing-Bablok regression analysis, Kolmogorov-Smirnov test, Cusum test, and Spearman Rank test were performed by use of XLSTAT, Live Science for MAC, version 2020. 4.1, Addinsoft. Other Statistical analyses and data handling were performed using StatView version 5.0 for MAC 1992-1998 SAS Institute Inc.

\section{Results}

\section{Relationship of LIC to SIR and R2*}

First, we investigated the relationship of biopsy LIC to the SI L/SI M-ratio, using TE $=25 \mathrm{~ms}(\mathrm{TR}=560 \mathrm{~ms})$, in the following called the SIR 25/560 method, according to the setup, we still use at our Department of Radiology. In total, 27 biopsy LIC measurements and corresponding SIR values were available for image analysis from 13 mini pigs. The numbers of examinations, contributed by each pig, and iron-loading details are displayed in Fig. 2D. Biopsy LIC-values ranged from 0.62 to $34.2 \mathrm{mg} / \mathrm{g}$. Higher biopsy LIC values were excluded because their corresponding SI L levels equaled background levels. The results are displayed in Fig. 4A, showing a curvilinear relationship between the SI L/SI M-ratios and the biopsy LIC values. Data fitted an exponential model (Rho - 0.96, $p<0.001$, Spearman Rank correlation on a log-linear plot). The equation is given in the figure. The assessed calibration line is displayed in a reciprocal form in Fig. 4B. Its equation is given in the figure. The $95 \%$ CI was -3.86 to -3.66 for the slope and 2.31 to 2.68 for the intercept.

Then we studied the agreement between LIC estimates, predicted by the SIR 25/560 method, and the corresponding biopsy LIC measurements by the Bland-Altman analysis. Results are given in Fig. 4C and Table 3. 
Fig. 4 Estimation of LIC by the SIR 25/560 method and by R2* method. A and $\mathbf{B}$ display the relationship of the SI L/SI M-ratio to the biopsy LIC. In A data are fitted by an exponential model and in $\mathbf{B}$ by a linear model after log-transformation. D displays the relationship of R2* to biopsy LIC. Regression lines are given in red with $95 \%$ $\mathrm{CI}$ limits in gray. $\mathbf{C}$ displays an analysis of agreement between biopsy LIC and LIC estimated by the SIR 25/560 method and F between the SIR $25 / 560$ and the R2* method (Bland Altman analysis). The full, bold lines represent bias. Broken, blue lines represent $95 \% \mathrm{CI}$ for bias and $95 \% \mathrm{CI}$ for method agreement (broken, red lines). $\mathbf{E}$ shows the agreement between the SIR 25/560 and the R2* method investigated by linear regression. The regression line is given with $95 \%$ CI limits (gray lines) and line of identity (broken, black line). All linear regression analyses by the Passing-Bablok method. $N=27$
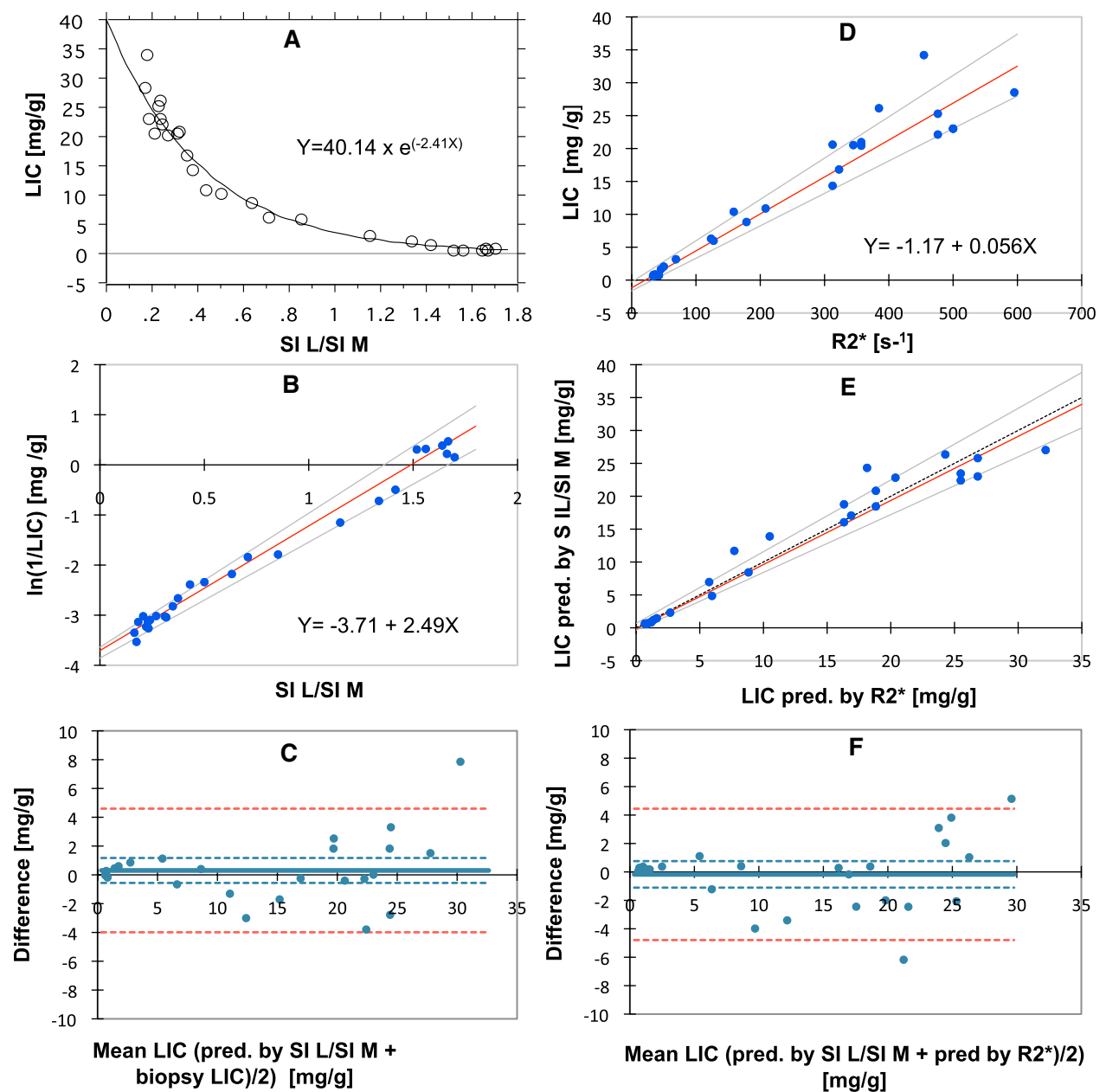

Table 3 Investigation of agreement between MRI methods and biopsy LIC by Bland-Altman analysis

\begin{tabular}{lll}
\hline Compared methods & 95\% CI of LoA & \\
& mg/g & $\%$ \\
\hline SIR contra biopsy & -4.0 to 4.60 & -29.90 to 39.94 \\
R2* contra biopsy & -5.27 to 6.21 & -41.29 to 39.79 \\
SIR contra R2 $*$ & -4.79 to 4.45 & -34.00 to 42.27 \\
\hline
\end{tabular}

$L o A$ limits of agreement, $C I$ confidence interval

The relationship of R2* to biopsy LIC values is displayed in Fig. 4D, showing the data fitted by a linear model (Rho $0.964, p<0.001)$. The $95 \%$ CIs were 0.05 to 0.06 for the slope and -1.62 to -0.30 for the intercept. Results of agreement analysis are given in Table 3 .

Then we studied the method agreement between LIC estimates, predicted by the SIR 25/560 method and by the R2* method, by the Bland-Altman analysis (Fig. 4F; Table 3). The analysis demonstrated a small bias of $-0.17 \mathrm{mg} / \mathrm{g}$ $(4.12 \%)$ with a $95 \%$ CI from -1.11 to $0.76 \mathrm{mg} / \mathrm{g}(-3.58$ to $11.82 \%)$. Investigation of the relation between LIC estimates, obtained by the SIR 25/560 method, and by the R2* method, revealed a linear relationship (Fig. 4E) with a slope of 0.974 (95\% CI 0.88 to 1.09), not different from 1 , indicating a proportionality slope, and an intercept of -0.131 (95\% CI -0.37 to 0.67$)$, not significantly different from zero, indicating no significant systematic difference between the methods.

\section{Transferability of the calibration curve from the pig model to patients}

We compared LIC values, predicted by use of the porcine calibration curve, assessed by the SIR 25/560 method, from SI L/SI M-ratios, assessed in the pigs, with LIC estimates, obtained by translation of the same SI L/SI M-ratios to LIC estimates, by use of the human calibration, still in use at our Department of Radiology for our SIR method. The same MRI machine and scanner software package was used for the patients and the pigs and the applied SE sequence, coil configuration, and imaging parameters were also identical, except a different TR (560 ms instead of $684 \mathrm{~ms})$. 
Figure 5A displays the relationship between LIC estimates, obtained by this human calibration $(\mathrm{TR}=684 \mathrm{~ms}$ ), and by the porcine calibration. The graph is not linear, primarily, because a different TR had been used for image acquisition in the pigs. To adjust the SI L/SI M-ratios for the difference in TR, we used two correction functions, implemented in the software package of our SIR method used for humans. For details, see the Materials and Methods. After correction of the SI L/SI M-ratios, the LIC values, predicted by the human calibration, were linearly correlated to those, predicted by the porcine calibration, (Fig. 5B). However, the calculated regression equation still indicated a systematic and a proportional difference between both calibrations: The slope coefficient of 0.84 (95\% CI 0.32 to 0.86 ) was significantly different from one, and the intercept of 0.81 (95\% CI 0.63 to 0.88 ) was significantly different from zero. Subsequent use of the regression equation from Fig. 5B as a correction function, led to an identity relationship between both LIC estimates (intercept 0.001 with $95 \%$ CI between -0.20 and 0.08 , and a slope of 1.0 with $95 \%$ CI from 0.98 to 1.02). Then, the Bland-Altman analysis showed a negligible bias of $0.08 \mathrm{mg} / \mathrm{g}$ with $95 \% \mathrm{CI}$ from -0.07 to $0.22 \mathrm{mg} / \mathrm{g}$ ( $0.12 \%$ with $95 \%$ CI from $-3.87 \%$ to $4.12 \%)$ and $95 \%$ LOAs

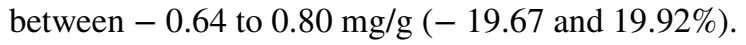

\section{Relation of biopsy LIC to SI L and the SI L/SI M-ratio when decreasing TE:}

Seventy-four MRI examinations were available for studying these relations. LIC values spanned from normal up to $150 \mathrm{mg} / \mathrm{g}$ in the liver biopsies from the most heavily ironloaded pigs. The numbers of examinations, contributed by each pig, and further iron-loading details are displayed in Fig. 2B. Figures 6A, B show how the reduction of TE from 25 to $12 \mathrm{~ms}$, while keeping TR at $560 \mathrm{~ms}$, influences SI L. As expected, the signal decays later at increasing LIC values using TE $12 \mathrm{~ms}$, compared to $25 \mathrm{~ms}$. Thus, SI $\mathrm{L}$ values below 25 were already seen around biopsy LIC values of $30 \mathrm{mg} / \mathrm{g}$ using $\mathrm{TE}=25 \mathrm{~ms}$, while, when applying $\mathrm{TE}=12 \mathrm{~ms}$, SI L still was around 120 . SI L values below 25 were first seen at around $100 \mathrm{mg} / \mathrm{g}$.
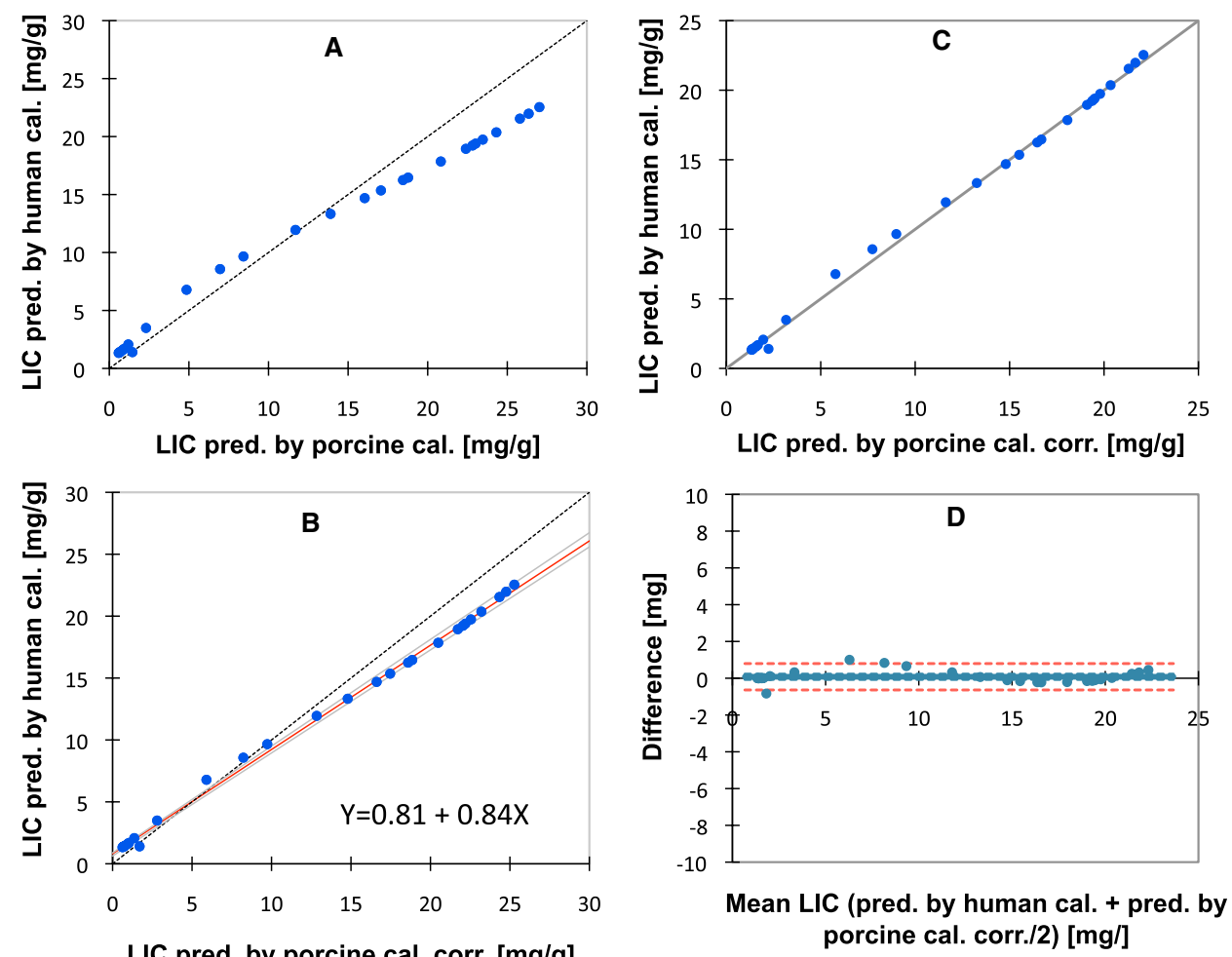

Fig. 5 Comparison of LIC estimates predicted by the porcine and a human calibration curve. A Displays the relationship between both predicted LIC estimates. The broken line is the line of identity. In $\mathbf{B}$ porcine SI L/SI M-ratios were corrected for the difference in TR at image acquisition. Linear regression by the Passing-Bablok method, given with 95\% CI limits (gray). The regression line is in red. The broken, black line is the line of identity. $\mathbf{C}$ shows agreement between

predicted LIC estimates with the line of identity, calculated by the human and porcine calibration, after correction of the porcine LIC estimates for the proportional and systematic differences, observed in $\mathbf{B}$, by use of the correction function displayed in B. D Displays the method agreement (Bland-Altman analysis). Data are the same as in C. The full, bold line represents bias. Broken lines represent 95\% CI for bias (blue), and 95\% CI for method agreement (red). $\mathrm{N}=27$ 
Fig. 6 Relation of biopsy LIC to SI L and SI L/SI M-ratio at different TRs and to T2*. The relationship for the SIR 25/560 method is given in $\mathbf{A}$ and $\mathbf{B}$ after decreasing TE from 25 to 12 ms. D Illustrates the relationship between $\mathrm{T} 2 *$ and biopsy LIC. C, E Illustrate the relationship between biopsy LIC and SI $\mathrm{L} / \mathrm{SI} \mathrm{M}$-ratio at $\mathrm{TE}=12 \mathrm{~ms}$, in panel $\mathrm{E}$ fitted by an exponential model and in $\mathbf{C}$ by a linear model after log-transformation of biopsy LIC values (PassingBablok method). $N=74$
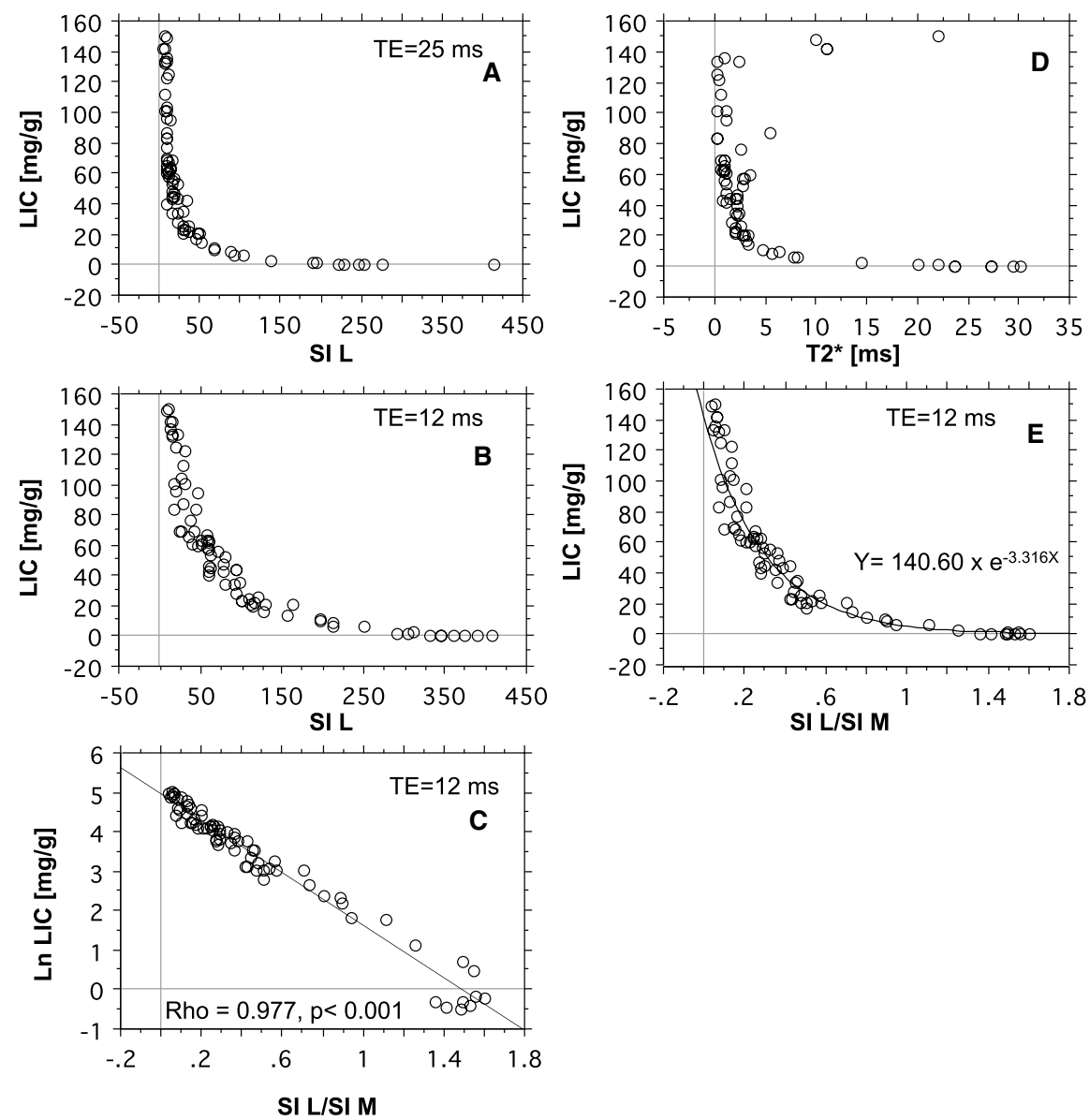

Figure 6D illustrates the relation between biopsy LIC and hepatic $\mathrm{T} 2 *$. The relationship has a similar shape as for the SIR 25/560 method: T2* values approached zero when LIC values exceeded around 35 to $40 \mathrm{mg} / \mathrm{g}$, due to lack of signal intensity.

Figure 6E shows how the SI L/SI M-ratios are related to biopsy LIC values, at TE $=12$. Data fitted an exponential model. Moreover, the measuring range of LIC values is markedly increased, compared to the SIR 25/560 method and the R2* method. LIC values within the normal range and up to around $115 \mathrm{mg} / \mathrm{g}$ are fitted by the exponential model. Log transformation of the LIC values resulted in a close, linear relationship $(\mathrm{Rho}=0.98$, $p<0.001$ ), (Fig. 6C). Despite a high Rho value, at $\mathrm{S}$ IL/S IM ratios $>0.4$, corresponding to $\ln$ LIC $<3.5$ (equals $<34 \mathrm{mg} / \mathrm{g}$ ), data were not fitted very well by the model.

\section{Influence of TR on the relationship between SI L, SI L/SI M-ratio, and chemical LIC}

We examined whether a change of TR might improve the degree of correlation between biopsy LIC values and SI $\mathrm{L}$ values and SI L/SI M ratios, especially within the LIC range below $34 \mathrm{mg} / \mathrm{g}$. MR images were, therefore, acquired at six different TRs (300, 400, 600, 800, 1000, and $1200 \mathrm{~ms})$. Eighty-one MRI examinations ( 54 at $\mathrm{TR}=300 \mathrm{~ms}$ ), were performed in 13 pigs. As the exponential model did not fit LIC values of more than around $115 \mathrm{mg} / \mathrm{g}$ very well, we decided to exclude values $\geq 115 \mathrm{mg} / \mathrm{g}$ (11 examinations with LIC values from 117.5 to $143 \mathrm{mg} / \mathrm{g}$ ), leaving 70 examinations (43 examinations at $\mathrm{TR}=300 \mathrm{~ms}$ ). The numbers of examinations, contributed by each pig, and further ironloading details are displayed in Fig. 2C, E.

Figure 7A-F shows how the SI L/SI M-ratio is related to the log-transformed LIC when using different TRs. The 
Fig. 7 Relationship of biopsy LIC to SI L and SI L/SI M-ratio at different TRs. The relationship was studied at six different TRs, as indicated in each panel. TE was $12 \mathrm{~ms}$. A-F Displays the relationship for SI L/SI M-ratio and panel G to L for SI L. Linear regression analyses by the Passing-Bablok method. Correlation analysis by Spearman Rank test. $N=43$ at $\mathrm{TR}=300 \mathrm{~ms}$ and $\mathrm{N}=70$ at longer TRs.
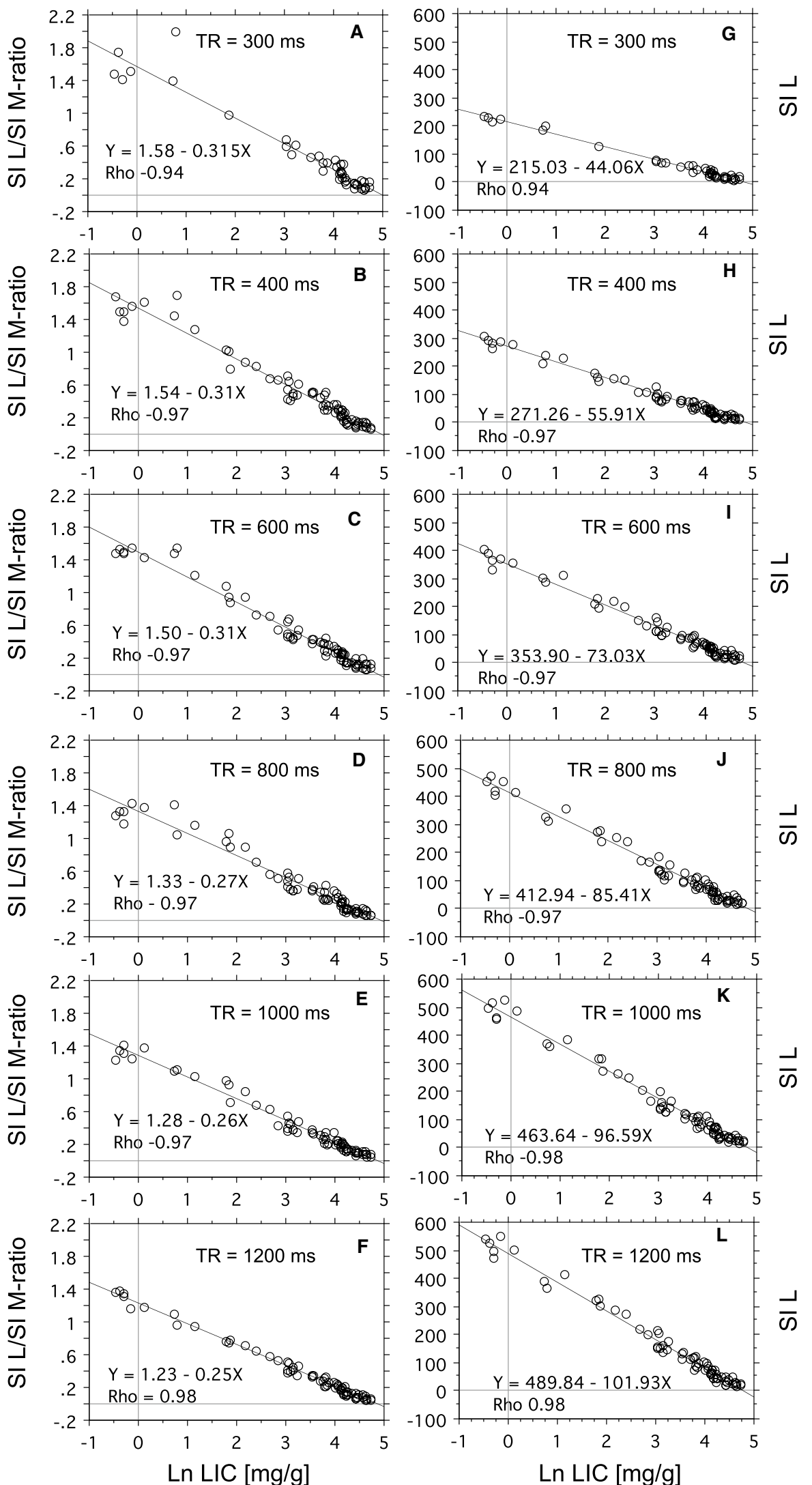
Fig. 8 Variance around calibration curves, depending on the applied TR and use of the tissue reference, investigated by LME modeling. The analysis is based on the same data as Fig. 7. Pointwise standard deviations as a function of the SI L/SI M-ratios (A) and SI L values (B) are plotted for each model. For more details, see the Statistics. C Displays the calibration curve with the lowest variance, using $\mathrm{TR}=1200 \mathrm{~ms}$ and the tissue reference (SIR12/1200 method). The regression line is in red (assessed by PassingBablok analysis), given with 95\% CI limits (gray lines). D shows the agreement between biopsy LIC values and those predicted by the calibration curve from $\mathbf{C}$ (Bland-Altman analysis). The full, bold line represents the bias. Blue, broken lines represent $95 \%$ CI for bias, and red, broken lines the 95\% CI for method agreement
TR

TR
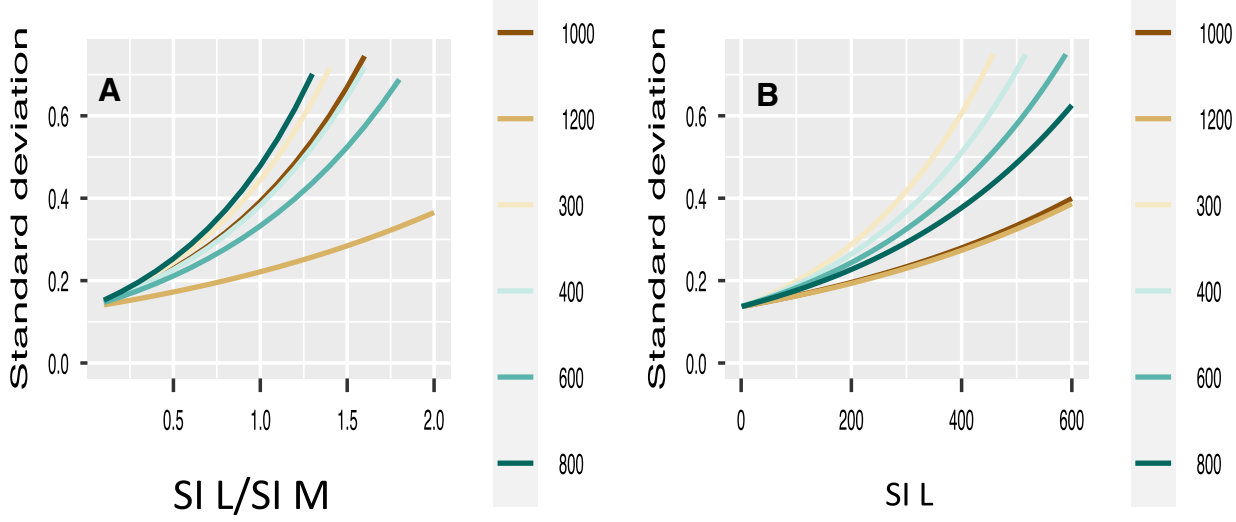

SI L

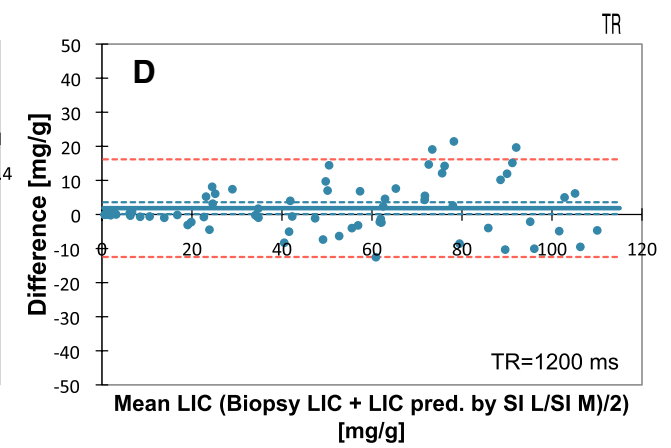

strength of the relationship was studied by Spearman's Rho. According to this test, the strength of the relationship was not influenced by the selection of TR between 400 and $1200 \mathrm{~ms}$ (Rho -0.97 to 0.98 ), except at $300 \mathrm{~ms}$, showing a weaker relationship (Rho - 0.94).

As Spearman's Rho is a measure of correlation, but not a measure of linearity, we also used LME to find the TR value leading to the calibration line with the lowest variance (for details see the statistics). The results are displayed in Fig. 8A. The LME model identified TR $=1200 \mathrm{~ms}$ as the calibration curve with the lowest variance, increasing exponentially from around $0.1 \mathrm{SD}$ at the highest to around $0.4 \mathrm{SD}$ at the lowest LIC values. Moreover, at high LIC values $\geq 34 \mathrm{mg} / \mathrm{g}$, corresponding to SI L/SI M-ratios $<0.4$, the model indicated small differences in variance between calibration curves at different TRs.

\section{Significance of the skeletal muscle as reference tissue}

To investigate the usefulness of the skeletal muscle as reference tissue, we investigated, if SI L/SI M (Fig. 7A-F) or SI L (Fig. 7G-L) was more closely related to Ln biopsy LIC, by comparing Spearman's Rho. We found that the use of the muscle reference had no improving impact on the degree of correlation at any TR, as all Rho values were the same when using the reference or not. However, an inspection of panels F and L of Fig. 7 suggested a better linear model fit when using the reference at lower LIC levels (SI L/SI M ratios $\geq 0.4$ ) when using TR $=1200 \mathrm{~ms}$. Looking at the LME models (Fig. 8A, B) confirms this effect of the use of the reference within the low LIC range, by demonstrating a slightly less steep variance curve at $\mathrm{TR}=1200 \mathrm{~ms}$. Moreover, the models also demonstrated a much steeper increase of the variance curves at lower TRs when using the reference.

As the model indicated different strengths of the relationship between biopsy LIC and MRI-estimated LIC at high and low LIC range, we studied the relationship within the range $<34 \mathrm{mg} / \mathrm{g}$ and $\geq 34$ to $<115 \mathrm{mg} / \mathrm{g}$ by calculating $\mathrm{R}^{2}$ (data were normally distributed in the two LIC subsets). The results are shown in Table 4. Overall, the use of the reference slightly increased $R^{2}$ at TR $=1200 \mathrm{~ms}$ within both LIC ranges, while at lower TRs, the reference had no effect within the high range, but within the low range, all $R^{2}$ values were lower when using the reference.

Finally, we studied the agreement between biopsy LICs and LIC estimates, calculated by using the best calibration curve, with the lowest variance, covering the whole LIC range (from normal to $<115 \mathrm{mg} / \mathrm{g}$ ), assessed by the use of TR $=1200 \mathrm{~ms}$ and $\mathrm{TE}=12 \mathrm{~ms}$, by Bland-Altman analysis (Fig. 8D). The 95\% LoAs between biopsy LIC and 
LIC estimates were from -12.47 to $16.18 \mathrm{mg} / \mathrm{g}(-24.58$ to $32.33 \%$ ) and there was only a small bias of $1.86 \mathrm{mg} / \mathrm{g}$ (3.88\%) with a $95 \%$ CI from 0.11 to $3.60 \mathrm{mg} / \mathrm{g}(0.42 \%$ to $7.34 \%)$. The regression equation of this calibration curve is given in Fig. 8C.

\section{Discussion}

Today, most MRI methods for estimation of liver iron rely on the T2 [42] or T2* effect [35-40, 43, 44], because the relaxation enhancement effect of iron on $\mathrm{T} 2$ and $\mathrm{T} 2 *$ is much greater than on T1 [70]. In the present study, we compared our T1-weighted SIR 25/560 method with a T2* method. Agreement between biopsy and MRI-estimated LIC values was similar as well as the upper limit of the measuring range around $35 \mathrm{mg} / \mathrm{g}$. We optimized our SIR method to extend its limited measuring range. For these investigations, we used a mini-pig model of iron overload, because this enabled the calibration of the method over a wide LIC range.

\section{Comparison of LIC measuring range of our method with other methods}

Many studies, which have investigated the relationship between MRI-derived LIC estimates and the chemical LIC, include one or a few patients with LIC levels exceeding $40 \mathrm{mg} / \mathrm{g}$ dry weight $[25,34,36,40,71,72]$. These very high LIC values exceed the upper measurable range of 35 to $40 \mathrm{mg}$ of the R2* method of Wood et al.[36], are equal to or exceed the highest LIC levels estimated by the FerriScan ${ }^{\circledR}$ method[42], and significantly exceed the upper limit of the measuring range of our SIR 25/560 method of $30-35 \mathrm{mg} / \mathrm{g}$ [47].

In the present study, we were able to extend the upper LIC limit of the measuring range of our method to around $115 \mathrm{mg} / \mathrm{g}$. Such a high upper limit has not been reported before, and it is unlikely that patients with higher LIC levels will be encountered in clinical practice. The extension of the measuring range was achieved by studying the effect of changing of TE and TR on SI L and the SIR of liver tissue in iron-loaded mini pigs within a wide range of iron overload, including very high LIC values. As we had expected, the reduction of TE from 25 to $12 \mathrm{~ms}$ indeed caused a later decay of the SI L at high LIC values, extending the upper limit of the measuring range, but also led to a lower precision at low LIC values below $<34 \mathrm{mg} / \mathrm{g}$. These observations suggest a lower sensitivity to the iron of the applied T1-weighted sequence after TE reduction that appeared to be canceled within the low LIC range by choosing a longer TR.

An extension of the measuring range of the $\mathrm{R} 2 *$ method is also under investigation: Very recently a new, promising approach has been presented, based on the use of ultrashort echo time images $(<1 \mathrm{~ms})[73,74]$. Operating at 3 Tesla, the technique could reliably estimate high liver iron concentrations up to $50 \mathrm{mg} / \mathrm{g}$ dry weight [74]. It was concluded that further improvement to the protocol and fitting approaches may allow measuring low and moderate LIC with the same accuracy demonstrated at high iron concentrations. [74].

\section{Comparison of agreement between LIC assessed by biopsy and by MRI:}

Using the SIR 12/1200 method, the 95\% LoAs between biopsy LIC values and those, estimated by the SI L/SI $\mathrm{M}$ ratios, were -24.58 to $32.33 \%$. This range of LoAs is smaller than those published for the $\mathrm{T} 2 *$ method $(-46$ to 44\%) [36] and the FerriScan ${ }^{\circledR}$ method (- 56 to 50\%) [42]. The agreement was not investigated in the study of Gandon et al. [43]. There are several possible explanations for the better agreement as follows:

One likely explanation is that mini pigs do not develop liver fibrosis despite very severe, long-standing, hepatic iron loading with weekly dextran-iron injections [59]. In patients with iron-loading anemias and transfusional iron overload, liver fibrosis is a well-known complication [7-9]. Liver fibrosis has an important impact on the coefficient of variation (CV) of multiple measurements of the iron concentration in percutaneous needle biopsy from the liver. Thus, in non-diseased livers, CV values of $19 \%$ have been reported [75] and for cirrhotic livers, the CV has been reported to be as high as $41 \%$ [76]. The sampling error of the liver biopsy is regarded to be the major contributor to the span of LoA for the FerriScan ${ }^{\circledR}$, R2-based method [42] and also for the T2* method [36]. The underlying reason for the increased sampling error of biopsy LIC measurements with increasing fibrosis stages is the lack of iron in fibrous tissue and the spatial inhomogeneity of fibrosis within the liver [77].

A further potential explanation for the better agreement is that the lack of hepatic fibrosis in the mini pigs excludes a potential interference of fibrosis on the relaxation processes in the liver tissue in the present study. Thus, it has been shown that the presence of fibrosis within the liver may significantly increase the relaxation times $\mathrm{T} 1[78,79]$ and $\mathrm{T} 2$ [79] of the liver tissue. A similar interfering effect has also been claimed for R2* [80]. However, R2* was not found to be significantly related to low-grade fibrosis in a study of patients with transfusional iron overload [37].

Another likely reason is the larger sample weight of the percutaneous liver biopsy in the present study. Thus, it has been shown that the variability of LIC measurements increases with smaller biopsy samples less than $1 \mathrm{mg}$ dry weight [81]. The mean dry weight of the liver needle biopsies in the present study was $2.52 \pm 1.11 \mathrm{mg}$ in 81 samples. 
Table 4 Relationship between biopsy LIC and MRI estimatedLIC within low and high LIC range at different repetition times (TR)

\begin{tabular}{llllllll}
\hline LIC range & Method & \multicolumn{2}{l}{ TR $(\mathrm{ms})$} & & & \\
\cline { 3 - 7 } & & 300 & 400 & 600 & 800 & 1000 & 1200 \\
\hline Low & SI L/SI M-ratio & 0.81 & 0.91 & 0.94 & 0.90 & 0.95 & 0.99 \\
Low & SI L & 0.99 & 0.97 & 0.96 & 0.96 & 0.97 & 0.97 \\
High & SI L/SI M-ratio & 0.70 & 0.82 & 0.79 & 0.78 & 0.83 & 0.85 \\
High & SI L & 0.71 & 0.81 & 0.78 & 0.78 & 0.82 & 0.83 \\
\hline
\end{tabular}

Strength of the relationship was studied by calculating $R^{2}$. Low LIC range: $\leq 34 \mathrm{mg} / \mathrm{g}$; high LIC range: $>34$ to $<115 \mathrm{mg} / \mathrm{g}$.
Only five biopsies weighed less than $1 \mathrm{mg}$. In the study of Wood et al. [36], the range of sample weight, measured in four patients, was from 5.1 to $6.3 \mathrm{mg}$ wet weight, equaling 1.5 to $1.8 \mathrm{mg}$ dry weight. In the study of St Pierre et al. [42], all samples had a dry weight of more than $0.4 \mathrm{mg}$.

Moreover, the later decay of SI L at high LIC may have improved the agreement between LIC estimates by MRI and biopsy LIC levels, especially at high LIC levels. Also, the fact that liver biopsy and MRI always were performed on the same day, and the lack of motion artifacts due to the anesthesia of the pig, may all have contributed to a better agreement.

\section{The usefulness of the tissue reference}

The most important drawback of the SIR method, in contrast to the relaxometry methods, is the need for comparison of SIL to a reference tissue that does not accumulate iron, because the absolute signal intensity of a tissue, measured by MRI, is arbitrary and depends on imaging parameters [32]. Relaxometry methods do not need a tissue reference, because they model the signal intensity of a single tissue (e.g. liver) across multiple TEs, enabling the calculation of $\mathrm{T} 2$ and T2* [32]. The SIR method, used in the present study, applies skeletal muscle as the reference tissue, which has not been shown to accumulate iron despite heavy iron loading in mini pigs [59]. However, there is some indication of lack of inter-scanner reproducibility of SIR methods from one study [38] as follows: Alterations of the SIR of liver tissue were noticeable between scanners, which were ascribed to an observed variation of the signal intensity of the paraspinal muscle between different gradients and equipment.

In the present study, we found that the usefulness of the muscle reference depended on the applied TR and the level of LIC. This underlines the significance of selecting the optimal TR for a SIR method. This optimization can easiest be performed in a model of iron overload, supplying subjects with a wide range of different LICs, as it is possible with the mini-pig model used in the present study.

\section{Transferability of the calibration curve from pig model to patients}

Finally, it must be asked if the calibration curve for the SIR $12 / 1200$ method, optimized in the pig model, can directly be used for estimation of LIC in patients with iron overload. Although the pig model has been shown to simulate humans very well regarding anatomy, physiological and metabolic processes [82, 83], we found a proportional difference of around $16 \%$ when comparing the porcine with the human calibration curve for the SIR TE 25/560 method. The most likely explanation for this difference is the different processing of the liver tissue from the needle biopsy used for the determination of LIC. In the present study, desiccated tissue from fresh liver specimens was used, while for the human calibration, deparaffinized liver tissue samples were used. The paraffin embedding technique has been shown to overestimate the LIC $[84,85]$, most pronounced in the study of Butensky [84], demonstrating an overestimation of $23 \%$. Paraffin embedding of tissue samples includes washing in xylene, which dissolves lipids, reduces dry weight, and increases the iron-to-weight ratio compared to fresh samples [84]. This likely explanation of the difference suggests that the porcine calibration curve for the SIR 12/1200 method is also useful for the estimation of LIC in humans.

However, before the porcine calibration can be used for translation of SIR values to LIC values in humans, a study is necessary, comparing parallel LIC estimates, predicted from SIR values measured by the SIR 25/560 method and by the SIR 12/1200 method in humans with iron overload, and if possible, with parallel LIC measurements in desiccated fresh liver biopsy specimens from the patients. The lack of these data represents the most important limitation of the present study. Another limitation is that the SIR 12/1200 method has not yet been validated across different scanner types. This is relevant because limited inter-scanner reproducibility of SIR methods has been reported [38]. 


\section{Conclusion}

Various MR imaging techniques, each with their respective advantage and limitations, have been developed for the noninvasive estimation of LIC. The advantage of the presented SIR12/1200 method is the much wider measuring range, up to LIC values well above $100 \mathrm{mg} / \mathrm{g}$, and a good agreement between LIC values assessed by biopsy and by MRI, if appropriate scanning parameters are used. The extended measuring range is likely caused by lesser sensitivity of the SE sequence to iron, due to shorter TE, leading to later signal loss at high LIC. The advantages of the method will probably enable a proper non-invasive evaluation of a wide range of patients with iron overload, including the most severe cases.

Acknowledgements The author would like to thank the staff in Biomedical Research Laboratory at Aalborg University Hospital for their meticulous animal care and excellent technical assistance, including the application of the weekly dextran-iron injections. The author is grateful for the dextran iron (Uniferon ${ }^{\circledR}$ ) which has been supplied as a gift from Pharmacosmos A/S, Holbæk, Denmark.

Author contributions PDJ made the study conception and design, analyzed and interpreted data, and drafted the manuscript. AHN contributed to the acquisition of data. CWS contributed to the acquisition of data. KKJ contributed to the acquisition of data. MB contributed to the interpretation of data and statistical analysis. $\mathrm{ABHJ}$ contributed to the interpretation of data. BK contributed to the acquisition of data. All authors revised the manuscript critically and approved the final version.

Funding This work was supported by grants from the Obelske Familiefond (Grant no. 20461, 2015), Spar Nord Fond (Grant 2013), Aase og Ejnar Danielsen Fond (Grant no. 10-000912, 2013) and Karla og Verner Soerensens Almennyttige Forskningsfond (Grant nos. 701783, 2014 and 701783, 2018).

\section{Declarations}

Conflict of interest The authors declare that there are no conflict of interest.

Ethical approval Animal facilities and principles of laboratory and animal care conformed to the requirements of the Danish Animal Experiments Inspectorate (Stationsparken 31-33, DK-2600 Glostrup, Denmark). The present study was approved by this institution as well (Approval no. 2013-15-2934-00038).

Open Access This article is licensed under a Creative Commons Attribution 4.0 International License, which permits use, sharing, adaptation, distribution and reproduction in any medium or format, as long as you give appropriate credit to the original author(s) and the source, provide a link to the Creative Commons licence, and indicate if changes were made. The images or other third party material in this article are included in the article's Creative Commons licence, unless indicated otherwise in a credit line to the material. If material is not included in the article's Creative Commons licence and your intended use is not permitted by statutory regulation or exceeds the permitted use, you will need to obtain permission directly from the copyright holder. To view a copy of this licence, visit http://creativecommons.org/licenses/by/4.0/.

\section{References}

1. Brittenham GM, Badman DG, National Institute of D, Digestive, Kidney Diseases W (2003) Noninvasive measurement of iron: report of an NIDDK workshop. Blood 101(1):15-19

2. Pietrangelo A (2010) Hereditary hemochromatosis: pathogenesis, diagnosis, and treatment. Gastroenterology 139(2):393-408 e391-392

3. Wood JC (2014) Use of magnetic resonance imaging to monitor iron overload. Hematol Oncol Clin N Am 28(4):747-764,vii

4. St Pierre TG, Chua-anusorn W, Webb J, Macey D, Pootrakul P (1998) The form of iron oxide deposits in thalassemic tissues varies between different groups of patients: a comparison between Thai beta-thalassemia/hemoglobin E patients and Australian betathalassemia patients. Biochem Biophys Acta 1407(1):51-60

5. Brittenham GM (2011) Iron-chelating therapy for transfusional iron overload. N Engl J Med 364(2):146-156

6. Jensen PD, Jensen FT, Christensen T, Nielsen JL, Ellegaard J (2003) Relationship between hepatocellular injury and transfusional iron overload prior to and during iron chelation with desferrioxamine: a study in adult patients with acquired anemias. Blood 101(1):91-96

7. Berdoukas V, Bohane T, Tobias V, De Silva K, Fraser I, Aessopos A, Lindeman R (2005) Liver iron concentration and fibrosis in a cohort of transfusion-dependent patients on long-term desferrioxamine therapy. Hematol J 5(7):572-578

8. Olivieri NF (2001) Progression of iron overload in sickle cell disease. Semin Hematol 38(1 Suppl 1):57-62

9. Risdon RA, Barry M, Flynn DM (1975) Transfusional iron overload: the relationship between tissue iron concentration and hepatic fibrosis in thalassaemia. J Pathol 116(2):83-95

10. Modell B, Khan M, Darlison M (2000) Survival in beta-thalassaemia major in the UK: data from the UK Thalassaemia Register. Lancet 355(9220):2051-2052

11. Olivieri NF, Nathan DG, MacMillan JH, Wayne AS, Liu PP, McGee A, Martin M, Koren G, Cohen AR (1994) Survival in medically treated patients with homozygous beta-thalassemia. N Engl J Med 331(9):574-578

12. Borgna-Pignatti C, Rugolotto S, De Stefano P, Zhao H, Cappellini MD, Del Vecchio GC, Romeo MA, Forni GL, Gamberini MR, Ghilardi R, Piga A, Cnaan A (2004) Survival and complications in patients with thalassemia major treated with transfusion and deferoxamine. Haematologica 89(10):1187-1193

13. Telfer P, Coen PG, Christou S, Hadjigavriel M, Kolnakou A, Pangalou E, Pavlides N, Psiloines M, Simamonian K, Skordos G, Sitarou M, Angastiniotis M (2006) Survival of medically treated thalassemia patients in Cyprus Trends and risk factors over the period 1980-2004. Haematologica 91(9):1187-1192

14. Vullo C, De Sanctis V, Katz M, Wonke B, Hoffbrand AV, Bagni B, Torresani T, Tolis G, Masiero M, Di Palma A et al (1990) Endocrine abnormalities in thalassemia. Ann N Y Acad Sci 612:293-310

15. Angelucci E, Muretto P, Nicolucci A, Baronciani D, Erer B, Gaziev J, Ripalti M, Sodani P, Tomassoni S, Visani G, Lucarelli G (2002) Effects of iron overload and hepatitis C virus positivity in determining progression of liver fibrosis in thalassemia following bone marrow transplantation. Blood 100(1):17-21

16. Brittenham GM, Griffith PM, Nienhuis AW, McLaren CE, Young NS, Tucker EE, Allen CJ, Farrell DE, Harris JW (1994) Efficacy of deferoxamine in preventing complications of iron overload in patients with thalassemia major. N Engl J Med 331(9):567-573

17. Jensen PD, Jensen FT, Christensen T, Eiskjaer H, Baandrup U, Nielsen JL (2003) Evaluation of myocardial iron by magnetic resonance imaging during iron chelation therapy with deferrioxamine: indication of close relation between myocardial iron content and chelatable iron pool. Blood 101(11):4632-4639 
18. Wood JC, Kang BP, Thompson A, Giardina P, Harmatz P, Glynos T, Paley C, Coates TD (2010) The effect of deferasirox on cardiac iron in thalassemia major: impact of total body iron stores. Blood 116(4):537-543

19. Telfer PT, Prestcott E, Holden S, Walker M, Hoffbrand AV, Wonke B (2000) Hepatic iron concentration combined with long-term monitoring of serum ferritin to predict complications of iron overload in thalassaemia major. Br J Haematol 110(4):971-977

20. Angelucci E, Brittenham GM, McLaren CE, Ripalti M, Baronciani D, Giardini C, Galimberti M, Polchi P, Lucarelli G (2000) Hepatic iron concentration and total body iron stores in thalassemia major. N Engl J Med 343(5):327-331

21. Brittenham GM (2015) Reference method for measurement of the hepatic iron concentration. Am J Hematol 90(2):85-86

22. Morgan EH, Walters MN (1963) Iron storage in human disease: fractionation of hepatic and splenic iron into ferritin and haemosiderin with histochemical correlations. J Clin Pathol 16(2):101-107

23. Barry M, Flynn DM, Letsky EA, Risdon RA (1974) Long-term chelation therapy in thalassaemia major: effect on liver iron concentration, liver histology, and clinical progress. Br Med J 2(5909): 16-20

24. Wood JC (2015) Estimating tissue iron burden: current status and future prospects. Br J Haematol 170(1):15-28

25. St Pierre TG, El-Beshlawy A, Elalfy M, Al Jefri A, Al Zir K, Daar S, Habr D, Kriemler-Krahn U, Taher A (2014) Multicenter validation of spin-density projection-assisted R2-MRI for the noninvasive measurement of liver iron concentration. Magn Reson Med 71(6):2215-2223

26. Angelucci E, Baronciani D, Lucarelli G, Baldassarri M, Galimberti M, Giardini C, Martinelli F, Polchi P, Polizzi V, Ripalti $M$ et al (1995) Needle liver biopsy in thalassaemia: analyses of diagnostic accuracy and safety in 1184 consecutive biopsies. $\mathrm{Br}$ J Haematol 89(4):757-761

27. Rockey DC, Caldwell SH, Goodman ZD, Nelson RC, Smith AD (2009) Liver biopsy. Hepatology 49(3):1017-1044

28. Khalifa A, Rockey DC (2020) The utility of liver biopsy in 2020. Curr Opin Gastroenterol 36(3):184-191

29. Remacha A, Sanz C, Contreras E, De Heredia CD, Grifols JR, Lozano M, Nunez GM, Salinas R, Corral M (2013) Guidelines on haemovigilance of post-transfusional iron overload. Blood Transfus 11(1):128-139

30. Ho PJ, Tay L, Lindeman R, Catley L, Bowden DK (2011) Australian guidelines for the assessment of iron overload and iron chelation in transfusion-dependent thalassaemia major, sickle cell disease and other congenital anaemias. Intern Med J 41(7):516-524

31. Angelucci E, Barosi G, Camaschella C, Cappellini MD, Cazzola M, Galanello R, Marchetti M, Piga A, Tura S (2008) Italian Society of Hematology practice guidelines for the management of iron overload in thalassemia major and related disorders. Haematologica 93(5):741-752

32. Sirlin CB, Reeder SB (2010) Magnetic resonance imaging quantification of liver iron. Magn Reson Imaging Clin N Am 18(3):359-381

33. Stark DD, Moseley ME, Bacon BR, Moss AA, Goldberg HI, Bass NM, James TL (1985) Magnetic resonance imaging and spectroscopy of hepatic iron overload. Radiology 154(1):137-142

34. Kaltwasser JP, Gottschalk R, Schalk KP, Hartl W (1990) Noninvasive quantitation of liver iron-overload by magnetic resonance imaging. Br J Haematol 74(3):360-363

35. Anderson LJ, Holden S, Davis B, Prescott E, Charrier CC, Bunce NH, Firmin DN, Wonke B, Porter J, Walker JM, Pennell DJ (2001) Cardiovascular T2-star (T2*) magnetic resonance for the early diagnosis of myocardial iron overload. Eur Heart $\mathrm{J}$ 22(23):2171-2179
36. Wood JC, Enriquez C, Ghugre N, Tyzka JM, Carson S, Nelson MD, Coates TD (2005) MRI R2 and R2* mapping accurately estimates hepatic iron concentration in transfusion-dependent thalassemia and sickle cell disease patients. Blood 106(4):1460-1465

37. Hankins JS, McCarville MB, Loeffler RB, Smeltzer MP, Onciu M, Hoffer FA, Li CS, Wang WC, Ware RE, Hillenbrand CM (2009) $\mathrm{R} 2 *$ magnetic resonance imaging of the liver in patients with iron overload. Blood 113(20):4853-4855

38. Virtanen JM, Komu ME, Parkkola RK (2008) Quantitative liver iron measurement by magnetic resonance imaging: in vitro and in vivo assessment of the liver to muscle signal intensity and the R2* methods. Magn Reson Imaging 26(8):1175-1182

39. Christoforidis A, Perifanis V, Spanos G, Vlachaki E, Economou M, Tsatra I, Athanassiou-Metaxa M (2009) MRI assessment of liver iron content in thalassamic patients with three different protocols: comparisons and correlations. Eur J Haematol 82(5):388-392

40. Garbowski MW, Carpenter JP, Smith G, Roughton M, Alam MH, He T, Pennell DJ, Porter JB (2014) Biopsy-based calibration of $\mathrm{T} 2 *$ magnetic resonance for estimation of liver iron concentration and comparison with R2 Ferriscan. J Cardiovasc Magn Reson Off J Soc Cardiovasc Magn Reson 16:40

41. Henninger B, Kremser C, Rauch S, Eder R, Zoller H, Finkenstedt A, Michaely HJ, Schocke M (2012) Evaluation of MR imaging with $\mathrm{T} 1$ and $\mathrm{T} 2 *$ mapping for the determination of hepatic iron overload. Eur Radiol 22(11):2478-2486

42. St Pierre TG, Clark PR, Chua-anusorn W, Fleming AJ, Jeffrey GP, Olynyk JK, Pootrakul P, Robins E, Lindeman R (2005) Noninvasive measurement and imaging of liver iron concentrations using proton magnetic resonance. Blood 105(2):855-861

43. Gandon Y, Olivie D, Guyader D, Aube C, Oberti F, Sebille V, Deugnier Y (2004) Non-invasive assessment of hepatic iron stores by MRI. Lancet 363(9406):357-362

44. Henninger B, Zoller H, Rauch S, Finkenstedt A, Schocke M, Jaschke W, Kremser C (2015) R2* relaxometry for the quantification of hepatic iron overload: biopsy-based calibration and comparison with the literature. Rofo 187(6):472-479

45. Henninger B, Alustiza J, Garbowski M, Gandon Y (2020) Practical guide to quantification of hepatic iron with MRI. Eur Radiol 30(1):383-393

46. Meloni A, Luciani A, Positano V, De Marchi D, Valeri G, Restaino G, Cracolici E, Caruso V, Dell' amico MC, Favilli B, Lombardi M, Pepe A (2011) Single region of interest versus multislice T2* MRI approach for the quantification of hepatic iron overload. J Magn Reson Imaging JMRI 33(2):348-355

47. Jensen PD, Jensen FT, Christensen T, Ellegaard J (1994) Noninvasive assessment of tissue iron overload in the liver by magnetic resonance imaging. Br J Haematol 87(1):171-184

48. Jensen PD, Jensen FT, Christensen T, Ellegaard J (1995) Evaluation of transfusional iron overload before and during iron chelation by magnetic resonance imaging of the liver and determination of serum ferritin in adult non-thalassaemic patients. Br J Haematol 89(4):880-889

49. Chan YL, Li CK, Lam CW, Yu SC, Chik KW, To KF, Yeung DK, Howard R, Yuen PM (2001) Liver iron estimation in beta-thalassaemia: comparison of MRI biochemical assay and histological grading. Clin Radiol 56(11):911-916

50. Ooi GC, Khong PL, Chan GC, Chan KN, Chan KL, Lam W, Ng I, Ha SY (2004) Magnetic resonance screening of iron status in transfusion-dependent beta-thalassaemia patients. Br J Haematol 124(3):385-390

51. Johnston DL, Rice L, Vick GW 3rd, Hedrick TD, Rokey R (1989) Assessment of tissue iron overload by nuclear magnetic resonance imaging. Am J Med 87(1):40-47

52. Engelhardt R, Langkowski JH, Fischer R, Nielsen P, Kooijman H, Heinrich HC, Bucheler E (1994) Liver iron quantification: studies 
in aqueous iron solutions, iron overloaded rats, and patients with hereditary hemochromatosis. Magn Reson Imaging 12(7):999-1007

53. Sheth S, Allen CJ, Farrell DE, Tripp JH, Jafari R, Wang Y, Brittenham GM (2019) Measurement of the liver iron concentration in transfusional iron overload by MRI R2* and by high-transitiontemperature superconducting magnetic susceptometry. Clin Imaging 55:65-70

54. Fischer R, Piga A, Harmatz P, Nielsen P (2005) Monitoring longterm efficacy of iron chelation treatment with biomagnetic liver susceptometry. Ann N Y Acad Sci 1054:350-357

55. Gianesin B, Zefiro D, Musso M, Rosa A, Bruzzone C, Balocco M, Carrara P, Bacigalupo L, Banderali S, Rollandi GA, Gambaro M, Marinelli M, Forni GL (2012) Measurement of liver iron overload: noninvasive calibration of MRI-R2* by magnetic iron detector susceptometer. Magn Reson Med 67(6):1782-1786

56. Carneiro AA, Baffa O, Fernandes JP, Zago MA (2002) Theoretical evaluation of the susceptometric measurement of iron in human liver by four different susceptometers. Physiol Meas 23(4):683-693

57. Brittenham GM, Sheth S, Allen CJ, Farrell DE (2001) Noninvasive methods for quantitative assessment of transfusional iron overload in sickle cell disease. Semin Hematol 38(1 Suppl 1):37-56

58. Pavitt HL, Aydinok Y, El-Beshlawy A, Bayraktaroglu S, Ibrahim AS, Hamdy MM, Pang W, Sharples C, St Pierre TG (2011) The effect of reducing repetition time TR on the measurement of liver R2 for the purpose of measuring liver iron concentration. Magn Reson Med 65(5):1346-1351

59. Jensen PD, Nielsen AH, Simonsen CW, Baandrup UT, Vyberg M, Jensen SE, Magnusdottir SO, Krarup HB, Nielsen MF, Kjaergaard B (2020) Consequences of parenteral iron-dextran loading investigated in minipigs. A new model of transfusional iron overload. Blood Cells Mol Dis 83:102440

60. Jensen PD, Nielsen AH, Simonsen CW, Baandrup UT, Jensen SE, Bogsted M, Magnusdottir SO, Jensen ABH, Kjaergaard $\mathrm{B}$ (2021) In vivo calibration of the $\mathrm{T} 2 *$ cardiovascular magnetic resonance method at $15 \mathrm{~T}$ for estimation of cardiac iron in a minipig model of transfusional iron overload. J Cardiovasc Magn Reson Off J Soc Cardiovasc Magn Reson 23(1):27

61. Golberg L, Smith JP, Martin LE (1957) The effects of intensive and prolonged administration of iron parenterally in animals. Br J Exp Pathol 38(3):297-311

62. Beykan S, Dam JS, Eberlein U, Kaufmann J, Kjaergaard B, Jodal L, Bouterfa H, Bejot R, Lassmann M, Jensen SB (2016) (177)Lu-OPS201 targeting somatostatin receptors: in vivo biodistribution and dosimetry in a pig model. EJNMMI Res 6(1):50

63. Bollen JAH, Alstrup AKO (2010) The laboratory swine, vol 1. The laboratory animal pocket reference series. CRC Press Taylor \& Francis Group Boca Raton, FL 33487-2742

64. Chow PK, Jeyaraj P, Tan SY, Cheong SF, Soo KC (1997) Serial ultrasound-guided percutaneous liver biopsy in a partial hepatectomy porcine model: a new technique in the study of liver regeneration. J Surg Res 70(2):134-137

65. He T (2014) Cardiovascular magnetic resonance $\mathrm{T} 2 *$ for tissue iron assessment in the heart. Quant Imaging Med Surg 4(5):407-412

66. Bland JM, Altman DG (1999) Measuring agreement in method comparison studies. Stat Methods Med Res 8(2):135-160

67. Chihwa K, Ross SL (1995) A cusum test in the linear regression model with serially correlated disturbances. Economet Rev 14(3):331-346

68. Passing H, Bablok, (1983) A new biometrical procedure for testing the equality of measurements from two different analytical methods Application of linear regression procedures for method comparison studies in clinical chemistry Part I. J Clin Chem Clin Biochem Zeitschrift fur klinische Chem und Klinische Biochem 21(11):709-720
69. Pinheiro JCB (2000) Mixed effects modes in S and S-Plus. Springer, Statistics and Computing

70. Stark DD (1991) Hepatic iron overload: paramagnetic pathology. Radiology 179(2):333-335

71. Angelucci E, Giovagnoni A, Valeri G, Paci E, Ripalti M, Muretto P, McLaren C, Brittenham GM, Lucarelli G (1997) Limitations of magnetic resonance imaging in measurement of hepatic iron. Blood 90(12):4736-4742

72. Gandon Y, Guyader D, Heautot JF, Reda MI, Yaouanq J, Buhe T, Brissot P, Carsin M, Deugnier Y (1994) Hemochromatosis: diagnosis and quantification of liver iron with gradient-echo MR imaging. Radiology 193(2):533-538

73. Krafft AJ, Loeffler RB, Song R, Tipirneni-Sajja A, McCarville MB, Robson MD, Hankins JS, Hillenbrand CM (2017) Quantitative ultrashort echo time imaging for assessment of massive iron overload at 15 and 3 Tesla. Magn Reson Med 78(5):1839-1851

74. Doyle EK, Toy K, Valdez B, Chia JM, Coates T, Wood JC (2018) Ultra-short echo time images quantify high liver iron. Magn Reson Med 79(3):1579-1585

75. Kreeftenberg HG, Koopman BJ, Huizenga JR, van Vilsteren T, Wolthers BG, Gips CH (1984) Measurement of iron in liver biopsies-a comparison of three analytical methods. Clin Chim Acta Int J Clin Chem 144 (2-3):255-262.

76. Emond MJ, Bronner MP, Carlson TH, Lin M, Labbe RF, Kowdley KV (1999) Quantitative study of the variability of hepatic iron concentrations. Clin Chem 45(3):340-346

77. Clark PR, Chua-Anusorn W, St Pierre TG (2003) Proton transverse relaxation rate (R2) images of liver tissue; mapping local tissue iron concentrations with MRI [corrected]. Magn Reson Med 49(3):572-575

78. Meneses A, Santabarbara JM, Romero JA, Aliaga R, Maceira AM, Moratal D (2021) Determination of non-invasive biomarkers for the assessment of fibrosis, steatosis and hepatic iron overload by MR image analysis. a pilot study. Diagnostics (Basel) 11(7)

79. Keevil SF, Alstead EM, Dolke G, Brooks AP, Armstrong P, Farthing MJ (1994) Non-invasive assessment of diffuse liver disease by in vivo measurement of proton nuclear magnetic resonance relaxation times at $0.08 \mathrm{~T}$. Br J Radiol 67(803):1083-1087

80. Li J, Lin H, Liu T, Zhang Z, Prince MR, Gillen K, Yan X, Song Q, Hua T, Zhao X, Zhang M, Zhao Y, Li G, Tang G, Yang G, Brittenham GM, Wang Y (2018) Quantitative susceptibility mapping (QSM) minimizes interference from cellular pathology in R2* estimation of liver iron concentration. J Magn Reson Imaging JMRI 48(4):1069-1079

81. Urru SA, Tandurella I, Capasso M, Usala E, Baronciani D, Giardini C, Visani G, Angelucci E (2015) Reproducibility of liver iron concentration measured on a biopsy sample: a validation study in vivo. Am J Hematol 90(2):87-90

82. Miller ER, Ullrey DE (1987) The pig as a model for human nutrition. Annu Rev Nutr 7:361-382

83. Swindle MM, Makin A, Herron AJ, Clubb FJ Jr, Frazier KS (2012) Swine as models in biomedical research and toxicology testing. Vet Pathol 49(2):344-356

84. Butensky E, Fischer R, Hudes M, Schumacher L, Williams R, Moyer TP, Vichinsky E, Harmatz P (2005) Variability in hepatic iron concentration in percutaneous needle biopsy specimens from patients with transfusional hemosiderosis. Am J Clin Pathol 123(1):146-152

85. Beilby JP, Prins AW, Swanson NR (1999) Determination of hepatic iron concentration in fresh and paraffin-embedded tissue. Clin Chem 45(4):573-574

Publisher's Note Springer Nature remains neutral with regard to jurisdictional claims in published maps and institutional affiliations. 